\title{
Policy Futures Markets with Multiple Goals
}

\author{
Aaron L. Jackson* \\ Bentley University - Department of Economics \\ 175 Forest St. \\ Waltham, MA 02452-4705 \\ Phone: 781-891-3483 \\ email: ajackson@bentley.edu
}

July 17, 2009

\begin{abstract}
Previous work in monetary policy futures markets under a single policy goal have shown this approach to be effective at eliminating the circularity problem inherent with private-sector targeting strategies. We extend this monetary policy setting framework to a typical multiple goal policy objective: inflation and output stabilization. We also demonstrate how the prices in policy futures markets can help resolve debates over important policy questions.

JEL Classification: E42, E44, E52, G13

Keywords: Policy futures market, forecast targeting, monetary targets, prediction markets, information markets.
\end{abstract}

${ }^{*}$ I would like to thank Scott Sumner for immensely valuable feedback on earlier drafts. All errors or omissions are my own. 


\title{
Policy Futures Markets with Multiple Goals
}

\begin{abstract}
Previous work in monetary policy futures markets under a single policy goal have shown this approach to be effective at eliminating the circularity problem inherent with private-sector targeting strategies. We extend this monetary policy setting framework to a typical multiple goal policy objective: inflation and output stabilization. We also demonstrate how the prices in policy futures markets can help resolve debates over important policy questions.
\end{abstract}

JEL Classification: E42, E44, E52, G13

Keywords: Policy futures market, forecast targeting, inflation targets, prediction markets, information markets. 


\section{Introduction}

Because monetary policy affects the economy with a lag, observers such as Svensson (1997) have proposed that central banks target private-sector forecasts of future inflation. Bernanke and Woodford (1997) point out this approach to targeting forecasts of inflation can be problematic: As stabilization of the goal variable is achieved, no useful information about the state of the economy is gained from private agents, and hence transmitted to the policymaking authority. Thus, perfect stabilization of the goal variable(s) becomes impossible.

Jackson and Sumner (2006) discuss a way around this 'circularity problem' by proposing a futures market in which the value of a policy futures instrument is linked to the ratio of the policy goal variable (e.g., an inflation target) and the policy instrument (e.g., the fed funds rate). The model of Jackson and Sumner (2006) is part of a larger literature on economic uses of prediction markets, as described by Wolfers and Zitzewitz (2004), Hanson (2008), and Hahn and Tetlock (2005), among others. An important distinction between the proposal of Jackson and Sumner, and (prediction) markets that currently exist, is that a policy futures market generally involves setting policy directly in response to outcomes of the market, whereas existing (prediction) markets have no explicit bearing on the operational aspects of policy. For instance, liquid fed funds futures contracts are traded at the Chicago Board of Trade, however the outcomes of this market are a reflection of what the market thinks the Fed will do, but the Fed is under no obligation to set policy according to the market consensus.

Some earlier proposals to integrate private-sector markets into the setting of monetary policy include Hall (1983), Hetzel (1990), Sumner (1989), and Dowd (1994). Several of these papers are susceptible to the same circularity problem described above. These four proposals all focused on singular nominal targets, 
usually some measure of either the price level, inflation rate, or nominal GNP. As demonstrated in this paper, in addition to addressing the circularity problem, we consider multiple targets, including stabilization of real variables.

Recent innovative proposals for the use of futures markets to guide policy include Sumner (2006), who investigates the feasibility of extending the Federal Open Market Committee to the public, and Jackson and Sumner's (2009) proposal of using policy futures markets as a guide to global warming policy. Perhaps the most well-known attempt to use futures markets to guide policy is the U.S. Defense Department's proposal in 2003 of a Policy Analysis Market (PAM), which was designed to elicit information about geopolitical risk among Middle Eastern countries. It was highly controversial due to the widely held view that traders would be 'profiting from terrorism', and as a result was abandoned for political reasons.

Setting monetary policy according to the outcomes of a policy futures market has the advantages of transparency, as in a forecast targeting regime, efficiency in terms of aggregating and disseminating useful information, as well as simplicity: a credible central bank or policy setting authority simply sets policy based on realizations of futures market trading to achieve its stated goal. Policy futures traders using rational expectations provide an explicit forecast of the futures price, and an implicit forecast of the instrument.

For monetary policy regimes that have the singular goal of strict inflation targeting with little or no regard to cyclical variation in real activity, such as the Reserve Bank of New Zealand, an approach utilizing a policy futures market may be an innovative opportunity to gain further transparency and credibility for maintaining a nominal anchor. However, many central banks, even those with explicit inflation targets, attempt to stabilize competing goal variables to varying degrees, most commonly the dual goals of inflation and output stabi- 
lization. The policy futures market proposed by Jackson and Sumner analyzes only singular nominal targets and therefore ignores the practical concerns that most central banks would have under such a monetary regime. Indeed, in the context of a central bank's loss function, that paper analyzes only the special case where the implied weight on output stabilization in the central bank's loss function is zero.

As Cecchetti and Ehrmann (1999) find, there is considerable variation in the weight on inflation stabilization relative to output stabilization among central banks around the world, and most central banks (even among apparently 'strict' inflation targeters) choose to pay at least modest attention to output variability. Thus, in order for a monetary policy futures market to be considered practical as a policy framework, it needs to be demonstrated that such a regime can meet multiple policy objectives. Note that this is distinctly different from the debate over which policy goal or goals are best suited to enhance an economy's welfare (i.e. an inflation target, or a dual mandate as in the U.S.). This paper takes no formal stand over this debate, however it is demonstrated that such a monetary policy futures market could be useful in framing such a debate. Rather, the main concern in this paper is how central banks can most effectively use its resources to achieve those goals.

We address this concern by formalizing such a policymaking regime. In the next section we discuss the literature on private-sector forecast targeting, and the related literature on using prediction markets for policy purposes. In section 3 we extend the framework of Jackson and Sumner (2006) to include a central bank pursuing multiple policy objectives, and in Section 4 show how such a market could be useful in resolving important academic policy debates. Concluding remarks then follow. 


\section{Forecast Targeting and Prediction Markets}

\subsection{Forecast Targeting for Policy Purposes}

In the last decade or so, as information technology has proliferated in parallel with increasingly sophisticated financial innovations, many economists have raised the possibility of using private-sector forecasts of target variables to aid in dealing with lags in monetary policy effectiveness. This approach is advantageous to the central bank since it receives feedback in the current period about the effectiveness of policies which have an effect in the future. For instance, if private-sector forecasters believe inflation will rise at some horizon in the future, current policy can be tightened until expected inflation is in line with the target inflation rate over that horizon.

However, as Bernanke and Woodford (1997) show, as the policymaking authority becomes more successful at stabilizing expectations of the future value of the target variable, the signal-to-noise ratio declines. With perfect stabilization (but for unpredictable shocks), private-sector agents are unable to provide useful information about the target variable, thus the central bank can no longer make use of private-sector forecasts in conducting policy. Bernanke and Woodford did suggest that the circularity problem described above could be alleviated if "policymakers draw information from a variety of sources." However, because of their concerns about indeterminacy, Bernanke and Woodford didn't put much emphasis on overcoming the circularity problem and concluded that there is no substitute for a central bank relying on a structural model to implement policy.

Jackson and Sumner (2006) address Bernanke and Woodford's criticism by proposing policymakers base policy on a single indicator variable which is the ratio of the target variable and the instrument variable. Their paper demonstrates that a policy futures market can be constructed such that the central bank is utilizing only private-sector information, and is free of the circularity 
problem. The implication is that the central bank does not require a structural model when implementing policy, as the central bank can fully stabilize the economy by setting its instrument exclusively according to private-sector information.

A policy futures market consists of the central bank announcing the goal for a target variable or variables in advance. Participants in an open (prediction) market trade 'policy futures', in which the futures contracts are linked to the ratio of the realization of the policy goal variables for the period in which the policy will be effective, and the current instrument setting. Once a goal is announced, participants determine the appropriate value for the policy futures contracts through trading, and at the end of trading the central bank uses this information to set its instrument. This approach sidesteps the circularity problem by having private-sector forecasts of the goal variable(s) contingent on a setting of the monetary policy instrument. In addition, it produces the theoretical minimum variance for the target variable, meaning that the economy is on the policy frontier.

A forecast targeting regime relies on the assumption that the private-sector has information about the state of the economy which is useful in the policymaking process that the central bank may not have. There are arguments on both sides of the debate about whether the central bank or the private-sector has 'better' information about the economy. ${ }^{1}$ However, a seemingly more important issue is how that information is used.

\subsection{Why Market Based Policy?}

There is increasing evidence that decentralized, market-based mechanisms of aggregating diverse and incomplete information produce better outcomes than

\footnotetext{
${ }^{1}$ See Romer and Romer (2000) for evidence favoring superiority of central bank information, and Faust et al. (2003) for convincing counterarguments.
} 
expert opinion, or even committees composed of experts. ${ }^{2}$ For instance, Gürkaynak and Wolfers (2006) analyze prediction markets for economic derivatives, and find that "these markets are remarkably well calibrated," and that "few of the behavioral anomalies present in surveys of professional forecasts survive in equilibrium."

Blinder and Morgan (2008) perform an experiment on whether monetary policy committees with designated leaders outperform those without leaders. Their findings indicate that decentralized committees can perform as well as committees with strong leadership. ${ }^{3}$ Taken to its logical extreme, this result provides a strong presumption in favor of the idea of allowing markets as a mechanism of decentralization, and in particular allowing markets as a surrogate to committees deciding policy. If leadership doesn't matter in the context of policy decisions, then the only question remaining is how to most effectively gather and use the information available to make those decisions. ${ }^{4}$ The academic evidence from existing prediction markets such as the Iowa Electronic Markets or intrade.com indicates that these markets are much more efficient than groups of experts, polls, or professionals. ${ }^{5}$

Some critics contend that despite the possible efficiencies of such market based solutions, policy is too important an institution to leave to markets. In particular, the possibility that these markets could be subject to manipulation for personal gain or to produce undesired outcomes is often cited as an insurmountable barrier to the practical use of markets for policy purposes. However,

\footnotetext{
${ }^{2}$ Surowieki (2004) gives an extensive array of anecdotal evidence supporting this proposition. For a more rigorous treatment of the issues and presentation of evidence, see the essays in Information Markets, such as Wolfers and Zitzewitz (2006) or Berg and Rietz (2006).

${ }^{3}$ See also Battaglini (2004) and Lombardelli et al. (2002) for similar arguments.

${ }^{4}$ In discussing the paper by Blinder and Morgan (2008) at a session on expertise in monetary policy at the American Economic Association meetings in January 2008, Justin Wolfers made precisely this point, advocating the use of prediction markets to guide monetary policy as an alternative to the "dysfunctional" nature of monetary policy by committee.

${ }^{5}$ See Wolfers and Zitzewitz (2004), Gurkaynak and Wolfers (2006), or Berg and Rietz $(2006)$.
} 
experimental and empirical evidence suggests these reservations may be unfounded. In an experimental setting, Hanson, Oprea, and Porter (2006) found that within a prediction market framework, manipulators were unable to distort price accuracy, as non-manipulators set lower threshold prices in response to manipulation attempts. ${ }^{6}$ Wolfers and Zitzewitz (2004) report on several studies analyzing attempts to manipulate prices in existing prediction markets, and conclude that although there may be some very short-term effects on prices, manipulation does not leave lasting effects on market prices and dynamics. ${ }^{7}$

As an additional practical consideration, Jackson and Sumner (2006) point out that in order to make such a monetary policy futures market operational, there are several institutional design issues that would need to be addressed:

- Would there be enough interest in such markets to generate sufficient liquidity for accurate price signals?

- How can we be sure that policymakers would credibly commit to setting policy according to these markets?

- How can the central bank and other traders guard against trader default?

- How can you overcome the disincentives of being the first to trade in such a market?

Jackson and Sumner explore several possible solutions to these problems. This includes a proposed comprehensive solution to all four points by creating a margin account for each trader that pays a rate of interest slightly above market. Their proposal suggests margin accounts would guard against trader default, be used as a facility to subsidize trading to generate sufficient liquidity if necessary, and subsidize early trading to encourage price discovery. Finally, the

\footnotetext{
${ }^{6}$ In fact, their results suggest that price accuracy may actually improve with manipulation attempts by attracting additional liquidity into the market.

${ }^{7}$ For additional review of the issues of market manipulation, see Hanson (2006).
} 
margin account could be used to pay a penalty payment to traders should the central bank fail to set its instrument in accordance with the market outcome, enhancing credibility in the policy futures market regime. The central bank's role in monetary policy, in a broad sense would then be to set policy goals, and to provide oversight, facilities, and management of the regulatory structure of such a policy futures market. ${ }^{8}$

A natural question is whether setting up such a seemingly cumbersome system would be necessary considering there already exist private-sector forecasts for a variety of economic indicators and horizons. Even if separate existing markets could be utilized, say, in inflation futures and fed funds futures, the central bank would likely still have to implement its own market for several reasons.

First, although there are no formal inflation futures markets, often times the TIPS spread is used as a de facto measure of future inflation, and is of course derived from private-sector (bond) markets. However, the accuracy of the spreads in these forecasts are notoriously fickle to liquidity differentials between the nominal and indexed markets, and for this reason are generally viewed as a modestly good indicator of the direction of inflation, but much less reliable as an accurate level indicator.

Second, considering there are currently no private markets that provide real (or nominal) GDP forecasts, the Fed would likely need to develop and subsidize these markets itself in order to attract sufficient liquidity.

Third, depending on how often the central bank decides to conduct policy operations it may find it easier to set up markets that are specifically designed to mature or expire in a particular way, on a specific date. Drawing on separate inflation futures, GDP futures, and fed funds futures markets with potentially different maturity dates would raise complications in that those contracts might not expire at the same time, or even more importantly, at the same time on the

\footnotetext{
${ }^{8}$ See Jackson and Sumner (2006) for a more detailed discussion of these issues.
} 
date at which the Fed wishes to conduct policy operations.

Finally, policy futures markets are designed to trade on the ratio of the policy goal to the policy instrument. In other words, traders are trading on a forecast of the goal variable contingent on a particular policy setting. Having separate markets for inflation futures and fed funds futures, for instance, would create a disconnect in this contingent setting of the policy instrument, and would then be subject to the circularity problem. This doesn't necessarily preclude the central bank from drawing on existing markets, but for a policy futures market to work effectively, it would most likely need to be designed so that the trading infrastructure is tailored specifically to support its monetary policy operations.

The timing of how frequently these markets would operate is a separate issue, but one that is certainly not problematic. In practice, the central bank could choose a policy setting frequency however often it deems appropriate and consistent with its desire to mitigate fluctuations (i.e. monthly, bimonthly, etc.). As is currently practiced with FOMC policy meetings, the central bank could hold instrument setting dates every six weeks, with actual market trading occurring the last one or two weeks prior to the policy setting day. If six weeks is viewed as too inflexible to be able to react to emergency policy situations, the central bank could explicitly commit to setting the policy instrument according to the trading mechanism "until the next policy meeting". As inter-meeting policy changes are fairly rare, this would imply a policy setting of every six weeks, but with the added flexibility of responding to significant and sudden shocks if deemed necessary. ${ }^{9}$ In this case, traders would be pricing in the probability of an inter-meeting policy change, which would have the added benefit of conducting some of the emergency policy change preemptively. If this system is viewed as impractical, the central bank could set policy weekly, or even daily

\footnotetext{
${ }^{9}$ In order to preserve credibility in the policy futures mechanism, the central bank would need to provide explicit guidelines about how it would determine when an inter-meeting policy change would be "necessary".
} 
as described in Sumner (2006).

The length of any trading session would be somewhat dependent on the frequency of policy setting. Having too long of a trading session may be superfluous, as people who trade closer to the end date would have better information about the state of the economy, and therefore would have little incentive to trade much earlier than this. ${ }^{10}$ Likewise, having too short a trading window, of say only a day or two, may not allow markets sufficient time to absorb enough liquidity to generate accurate price signals. If the policy setting frequency was relatively short, such as daily, a system similar to Sumner (2006) could be implemented which allows for short trading sessions that elicits informative price signals from traders. Ultimately, the central bank may find it desirable to expand or shorten the trading window to account for these factors as necessary.

Such a policymaking regime may seem quite fanciful today, but information technology, financial innovation, and central bank transparency are all converging in a way that should improve the policymaking process. Indeed, despite Bernanke's earlier concerns about indeterminacy and the circularity problem, as Chair of the Federal Open Market Committee, he has continued to express public interest in augmenting Fed forecasts with private-sector information. For instance, in a speech in November, Bernanke (2007) stated:

“...If practitioners in financial markets gain a better understanding of how policy is likely to respond to incoming information, asset prices and bond yields will tend to respond to economic data in ways that further central banks objectives. For example, if market participants understand that arriving information about the economy increases the likelihood of certain policy actions, then market interest rates will tend to move in a way that reinforces the expected actions, effectively supporting the goals of the central bank."

In other words, Bernanke is recognizing that with greater transparency of policy goals, and Fed projections conditional on settings of the instrument, the

\footnotetext{
${ }^{10}$ Hence the argument for subsidies to encourage early trading described above.
} 
private-sector can do much of the heavy lifting to effectuate policy changes. ${ }^{11}$ Mankiw (2006) has similarly recognized the potential role that the privatesector can play in facilitating a stable monetary policy that relies on market expectations. This is not to suggest that the likes of Mankiw and Bernanke would unequivocally endorse such a framework as is proposed here, but rather to demonstrate that policymakers are receptive to the idea of incorporating private-sector information into the policy process in a formal way. In the next section, we expand on this notion by formally constructing a monetary policy regime to handle multiple policy objectives while relying exclusively on privatesector information.

\section{Policy Futures Markets with Multiple Goals}

\subsection{Circularity, Indeterminacy, and Modelling}

In evaluating monetary policy efficacy, it is natural to consider how a given policy framework would perform within a specific structural model. However, there is currently little consensus about which structural model most appropriately represents the dynamics of a given economy. ${ }^{12}$ Even with an agreed upon structural model, there is the additional complication of what values the structural parameters take on, a difficult problem at best for a central bank trying to determine optimal policy.

Since policymakers are assumed to rely on the views of the private-sector when setting policy, there is no need for the central bank to presume any particular structural model of the economy. Individual private-sector traders have their

\footnotetext{
${ }^{11}$ Sumner (2008) provides an extensive analysis of the comments Bernanke made in this speech, particularly focusing on the implications for the role the Fed envisions the privatesector playing in the monetary policy process.

${ }^{12}$ Probably the closest to a 'consensus' model is the New Keynesian framework, detailed for instance, in Woodford (2003). However, even within this framework, there are substantial differences in modelling and behavioral assumptions that can be made, producing variation in structural model outcomes that can affect policy choice in non-trivial ways.
} 
own heterogeneous views of the world which motivates their trading activities. These heterogeneous views, when aggregated through the market mechanism, are likely to produce forecasts which, on average perform better than any individual (central bank) structural model, even if the central bank's structural model is far superior to most individual private-sector models. ${ }^{13}$ Moreover, if economists and policymakers knew the true structural model and parameters governing the economy, there would be little need to rely on private-sector information for policy guidance in the first place, which would seemingly preclude interest by proponents such as Bernanke and Mankiw.

For this reason, we utilize what is in essence a reduced form model of the private-sector's aggregate views to show that it is not necessary to rely on a structural model to implement efficient policy. This is not inconsistent with private-sector agents utilizing their own structural model to forecast goal variables or the instrument setting required to meet policy goals. For instance, under standard assumptions of New Keynesian staggered price-setting and an optimizing, forward-looking IS equation, a stable rational expectations equilibrium will result in a reduced form model similar to what is presented here (see Bernanke and Woodford, 1997, pp. 666-8).

In this sense, the exact specification of the model is inconsequential so long as the private-sector can convey the necessary information about the state of the economy to the central bank useful for stabilizing goal variables. The central bank need only determine what level to set its goal variables at, and a rule for setting its instrument as a function of the outcomes of the policy futures market, which is derived from the central bank's loss function. ${ }^{14}$ This policy approach

\footnotetext{
${ }^{13}$ Stix and Knell (2004) provide evidence of this in the context of estimating the income elasticity of money demand, finding that a typical individual forecast was much less accurate than the central bank's, yet the average of all individual forecasts was far superior to the central bank's forecast.

${ }^{14}$ Central banks may find a structural model useful in determining which variables to target, what those targets should be, or in deriving the optimal loss function. However, the point here is that the central bank does not need to rely on a structural model in the actual
} 
is shown to overcome the circularity issue raised by Bernanke and Woodford, as well as the assertion that a central bank must rely on an explicit structural model to guide policy decisions.

With respect to the indeterminacy (or solution multiplicity) issue of concern to Bernanke and Woodford, McCallum (2001, p. 153) suggests reasons why it may not be an obstacle, asserting that the problem "may not be of any practical significance." Additionally, in considering the relevance of indeterminacy in such a context, Jackson and Sumner (2006, p. 728) point out:

“...Our [policy futures market] proposal doesn't seem to depart from current practice in the United States and Europe in ways that would obviously trigger a problem of solution multiplicity. Bernanke and Woodford argued that policy needed to be based on a single structural model of the economy, but even under current practice Federal Open Market Committee votes aggregate information contained in 12 (implicit or explicit) structural models of the economy. In the case of the European Central Bank governing council, policy is based on as many as 17 structural models of the economy. Our proposal would envision an even larger set of decision makers, but it is difficult to see how that quantitative difference would suddenly create a problem of solution multiplicity."

If the indeterminacy issue is inconsequential, then the only obstacle to effectively harnessing private-sector forecasts for policy then is the circularity problem. Because we are concerned with demonstrating that the central bank can avoid the circularity problem without the use of a structural macromodel, we utilize a stylized model similar to Bernanke and Woodford (1997) and Woodford (1994).

implementation of policy. 


\subsection{The Model}

We demonstrate how a policy futures market would operate when there are two goals: an inflation target and an output target. ${ }^{15}$ Futures contracts traded in the policy futures market are linked to the ratio of the policy goal variable and the instrument. For the output contract, we define the output index as

$$
V_{t+1}^{Y} \equiv Y_{t+1}-I_{t}
$$

where $Y_{t}$ is $(\log )$ real output, and $I_{t}$ is the $(\log )$ instrument setting at time $t$. Any instrument, such as the short-term interest rate or the monetary base may be used, as long as the instrument is clearly defined and universally known by policy futures traders. Likewise, we define the inflation index as

$$
V_{t+1}^{\pi} \equiv \pi_{t+1}-I_{t}
$$

where $\pi_{t}$ is the $(\log )$ inflation rate.

We assume a one period lag in the effectiveness of policy on both inflation and output. Similar to Jackson and Sumner (2006), we assume that these processes evolve according to

$$
V_{t+1}^{Y}=\delta w_{t}+s_{t}+\alpha I_{t}+\varepsilon_{t+1}^{Y}
$$

and

$$
V_{t+1}^{\pi}=\gamma w_{t}+q_{t}+\beta I_{t}+\varepsilon_{t+1}^{\pi}
$$

noting that equations (3) and (4) reflect the implicit, aggregate views of all private-sector traders.

\footnotetext{
${ }^{15}$ An earlier version of this paper also extended the model to include instrument smoothing. The process could conceivably be extended beyond these goals; for simplicity we focus on inflation and output objectives since they are of primary concern to most central banks around the world.
} 
Each of the processes $V^{Y}$ and $V^{\pi}$ have four components. We assume a common state variable $w$ that influences both output and inflation. The idiosyncratic state variables $s$ and $q$, are independent of one another and capture unique influences on the specific processes $V^{Y}$ and $V^{\pi}$. The instrument setting $I_{t}$ will have an impact on the ultimate realization of $V^{Y}$ and $V^{\pi}$ (and also along with (1) and (2) directly affect $Y$ and $\pi$ ). Finally, there are idiosyncratic, white noise shocks, $\varepsilon_{t+1}$ that are unpredictable at time $t$.

By assumption, the central bank does not know $w, s$, and $q$ but would like to infer them from trading activities conducted by private-sector agents. The central bank does not need to know (3) or (4) to conduct policy.

At the beginning of period $t$ the central bank announces goals for its target variables, output $\left(Y^{*}\right)$ and inflation $\left(\pi^{*}\right) .{ }^{16}$ Once the targets are announced, participants in the policy futures market buy and sell contracts linked to their respective index values. Once trading has closed, the central bank uses the market price of the futures contracts, along with its preferences over inflation and output to set $I_{t}$.

As is common in the literature, a standard loss function (Svensson, (1997)) assumes the central bank wishes to minimize deviations of the goal variable from its targets. The private-sector forms expectations about future outcomes, and through its trading activities transmits information to the central bank via $V_{t+1}^{f, Y}$ and $V_{t+1}^{f, \pi}$. Policymakers use the implicit private-sector forecasts of output and inflation, $Y_{t+1}^{f}$ and $\pi_{t+1}^{f}$ to set policy.

In setting its instrument, the central bank minimizes its loss function

$$
L_{C B}=\lambda\left(Y_{t+1}^{f}-Y^{*}\right)^{2}+\left(\pi_{t+1}^{f}-\pi^{*}\right)^{2}
$$

\footnotetext{
${ }^{16}$ It is presumed that these goals would remain constant over medium to longer term horizons, consistent with the current practice at most inflation targeting central banks. Over longer periods of time, policymakers' views may evolve, initiating a change in policy targets. In theory, policymakers could adjust targets as frequently as desired, as long as the changes are announced well in advance of trading of the affected policy period.
} 
where $\lambda \geq 0$ dictates relative preferences over inflation and output. In order to appropriately price the traded indices, private-sector agents must know the central bank preferences. Given (1), (2), and (5) the central bank will set policy according to

$$
I_{t}=-\left(\frac{1}{1+\lambda}\right)\left[\lambda\left(V_{t+1}^{f, Y}-Y^{*}\right)+\left(V_{t+1}^{f, \pi}-\pi^{*}\right)\right] .
$$

Minimization of a quadratic loss function by private-sector agents requires $V_{t+1}^{f, Y}=$ $E_{t}\left(V_{t+1}^{Y} \mid w_{t}, s_{t}\right) \equiv E_{t} V_{t+1}^{Y}$ and $V_{t+1}^{f, \pi}=E_{t}\left(V_{t+1}^{\pi} \mid w_{t}, q_{t}\right) \equiv E_{t} V_{t+1}^{\pi}$. Once the private-sector reveals its forecasts $V^{f}$ at the close of the trading session, the central bank sets policy according to (6).

Since the private-sector is assumed to know (5) and hence (6) along with publicly stated policy targets for next period, private-sector traders can determine the rational expectations equilibrium (REE). Using the REE along with the instrument setting, the evolution of output can be determined according to (1) and (3). Likewise, the evolution of inflation is given using (2) and (4).

When the central bank utilizes the policy futures market for setting policy, given the REE implied by private-sector trading, the variance of output from target is given as

$$
\begin{aligned}
\operatorname{Var}\left(Y-Y^{*}\right)= & \sigma_{\varepsilon^{Y}}^{2}+\left[\frac{(1+\beta)}{\kappa}\right]^{2} \sigma_{s}^{2}+\left[\frac{(1+\alpha)}{\kappa}\right]^{2} \sigma_{q}^{2} \\
& +\left(\frac{1}{\kappa}\right)^{2}[\delta(1+\beta)-\gamma(1+\alpha)]^{2} \sigma_{w}^{2},
\end{aligned}
$$

where $\kappa \equiv 1+\beta+\lambda(1+\alpha)$. Note that when the central bank places no weight on inflation stabilization $(\lambda \rightarrow \infty)$, the variance of output from target is simply $\sigma_{\varepsilon^{Y}}^{2}$, the theoretical minimum. As $\lambda$ decreases, the central bank's goal of output stabilization becomes relatively less important than inflation stabilization and the variance of output becomes larger. When $\lambda=0$, the variance of output 
from target is equal to $\sigma_{\varepsilon^{Y}}^{2}+\sigma_{s}^{2}+\left(\frac{1+\alpha}{1+\beta}\right)^{2} \sigma_{q}^{2}+\left[\frac{\delta(1+\beta)-\gamma(1+\alpha)}{1+\beta}\right]^{2} \sigma_{w}^{2}$.

A similar procedure can be shown to yield an expression for the variance of inflation:

$$
\begin{aligned}
\operatorname{Var}\left(\pi-\pi^{*}\right)= & \sigma_{\varepsilon^{\pi}}^{2}+\left(\frac{\lambda(1+\beta)}{\kappa}\right)^{2} \sigma_{s}^{2}+\left(\frac{\lambda(1+\alpha)}{\kappa}\right)^{2} \sigma_{q}^{2} \\
& +\left(\frac{\lambda}{\kappa}\right)^{2}[\delta(1+\beta)-\gamma(1+\alpha)]^{2} \sigma_{w}^{2} .
\end{aligned}
$$

As $\lambda \rightarrow \infty$, the variance of inflation from target approaches $\operatorname{Var}\left(\pi-\pi^{*}\right)=\sigma_{\varepsilon^{\pi}}^{2}+$ $\left(\frac{1+\beta}{1+\alpha}\right)^{2} \sigma_{s}^{2}+\sigma_{q}^{2}+\left[\frac{\delta(1+\beta)-\gamma(1+\alpha)}{1+\alpha}\right]^{2} \sigma_{w}^{2}$. When $\lambda=0$, the variance of inflation is $\sigma_{\varepsilon^{\pi}}^{2}$, as would be expected if the central bank's policy setting resources were devoted only to inflation stabilization.

\subsection{Perfect Information by the Central Bank}

If the central bank has perfect information about the state of the economy, the central bank knows $w, s$, and $q$, and uses this information to set policy in a way that minimizes the loss function. Under rational expectations, the central bank will essentially use (1) - (4) and (6) to determine the instrument setting. Given its preferences over inflation and output stabilization, having perfect information results in stabilization outcomes on the efficient policy frontier. The central bank policy under perfect information results in the same instrument setting as under a policy futures regime (where it has essentially no information), hence resulting in the same efficient policy frontier outcomes for output and inflation realizations.

In other words, even if the central bank relies exclusively on private-sector information through the policy futures market, it can still achieve the theoretical minimum variance of output and inflation similar to if the central bank had full information about the state. Despite having no (explicit) information 
about the state of the economy, the central bank need only know (6), and the outcomes of the policy futures markets to efficiently stabilize the economy to meet its objectives. And, in contrast to the pessimistic conclusion of Bernanke and Woodford (1997), the policy futures market above does not exhibit the circularity problem.

The equivalent outcomes of the two regimes raise an interesting issue for the central bank. Under a policy futures market regime, the central bank effectively relinquishes control of the instrument setting to the private-sector. On the other hand, it is nearly costless from an information gathering perspective for the central bank to operate such a regime. In practice, gathering relevant information about the state can be costly, and at some point there will be little incentive to continue gathering additional information about the state, establishing a threshold stabilization point above the theoretical minimum dictated by the efficient policy frontier. However this is not unique to private-sector information gathering, as the central bank would face a similar problem given constraints on its resources.

These information constraints do not preclude the viability of a policy futures market regime. Private-sector traders will gather and trade on information up to the point where the profit motive is trumped by the high marginal cost of additional information. Once this occurs, private-sector agents may no longer have incentives to gather additional information about the state. In this case, the central bank may be able to subsidize private-sector information gathering to lower the threshold stabilization point, as this may be less costly than the central bank using its own resources in gathering information to conduct policy. 


\section{An Application of Policy Futures Markets: Re- solving Policy Debates}

An intriguing application of the policy futures market regime, besides its explicit role at executing policy, could be to assess the validity of macroeconomic policy debates. As one example, such a policy futures market could help address the monetary policy design question of which variable or variables should be targeted.

The targeting approach that has received the most attention has been that of inflation targeting, as this type of regime has been implemented in various forms by a growing number of central banks around the world. Although a full description of the issues is beyond the scope of this paper, proponents of the inflation targeting (IT) approach such as Svennson (1999) suggest that both output and inflation will be more stable under a strict IT regime, as opposed to McCallum (1999) among others, who advocate a nominal GDP target. McCallum contends that in the long-run, inflation control will be "almost as good" as under IT, while providing superior stabilization of real variables as a result of short-run disturbances.

As such, an interesting application of the policy futures market would be to examine where market participants stand on this or similar debates. Market participants are motivated by profit, thus the outcomes of the policy futures market should provide an unbiased view of the relative merits of each perspective.

Rather than the central bank minimizing a loss function as in (5), where $\lambda=0$ as in a strict inflation targeting regime, assume that policymakers are interested in pursuing a nominal GDP (growth) target, where now $Y$ is interpreted as the growth rate of real output. Thus, in a nominal GDP targeting 
regime, policymakers will want to minimize deviations of the sum of expected inflation $\pi_{t+1}^{f}$ and expected real GDP growth $Y_{t+1}^{f}$ from some target of nominal GDP growth $X_{t+1}^{*}$; that is, the central bank will want to set its instrument in such a way that

$$
\pi_{t+1}^{f}+Y_{t+1}^{f}=X_{t+1}^{*} .
$$

Given (1) and (2) this implies that the central bank will set the instrument according to the futures market outcomes as

$$
I_{t}=\frac{1}{2}\left[X_{t+1}^{*}-\left(V_{t+1}^{f, Y}+V_{t+1}^{f, \pi}\right)\right]
$$

It can be shown that under an REE, the equilibrium price of policy futures contracts will yield outcomes for the variance of output as

$$
\begin{aligned}
\operatorname{Var}(Y)_{N G D P} & =\sigma_{\varepsilon^{Y}}^{2}+\left[\frac{(1+\beta)}{2+\alpha+\beta}\right]^{2} \sigma_{s}^{2}+\left[\frac{(1+\alpha)}{2+\alpha+\beta}\right]^{2} \sigma_{q}^{2} \\
& +\left[\frac{\delta(1+\beta)-\gamma(1+\alpha)}{2+\alpha+\beta}\right]^{2} \sigma_{w}^{2}
\end{aligned}
$$

Under a strict inflation targeting regime, the variance of output is given as

$$
\operatorname{Var}(Y)_{I T}=\sigma_{\varepsilon^{Y}}^{2}+\sigma_{s}^{2}+\left[\frac{1+\alpha}{1+\beta}\right]^{2} \sigma_{q}^{2}+\left[\frac{\delta(1+\beta)-\gamma(1+\alpha)}{1+\beta}\right]^{2} \sigma_{w}^{2} .
$$

Thus, if a nominal GDP target is better at stabilizing output than is IT, it must be the case that $(1+\beta)^{2}<(2+\alpha+\beta)^{2}$. This is equivalent to the condition

$$
\beta>-\frac{1}{2}(\alpha+3)
$$


Given the beliefs of market participants about the values of $\alpha$ and $\beta$, to the extent that (12) holds this would support McCallum's assertion that a nominal GDP targeting approach is superior for stabilizing real variables. In other words, the aggregate market outcomes of the policy futures market (that is, the aggregate market views of $\alpha$ and $\beta$ ) implicitly reflect the market views of the debate over the effectiveness of an IT versus nominal GDP targeting regime. If there were mechanisms in place to induce traders to truthfully reveal $\alpha$ and $\beta$, this would provide an intriguing alternative to ideologically driven policy debate: resolution through a competitive profit motive. ${ }^{17}$

As it turns out, there are conditions under which such a signal extraction problem can be solved. The price of policy futures will continually be impacted by news about the state of the economy. Observing the immediate responses of traders to specific shocks allows for the values of $\alpha$ and $\beta$ to be backed out. For instance, news of an unexpected supply shock would be reflected in the state variable $q_{t} \cdot{ }^{18}$ If we assume that during a days' trading, no other meaningful shocks occur to affect the futures market prices, then the variation in prices during the day would presumably reflect variation in $q$.

To show one method for backing out the values for $\alpha$ and $\beta$, define $V_{t+1}^{f+} \equiv$ $V_{t+1}^{f, \pi}+V_{t+1}^{f, Y}$, the sum of the market prices of the traded inflation and output indices. A simple calculation shows that

$$
V_{t+1}^{f+}=\left(\frac{1}{2+\alpha+\beta}\right)\left[2(\gamma+\delta) w_{t}+2 s_{t}+2 q_{t}+(\alpha+\beta) X_{t+1}^{*}\right] .
$$

Observable variation in futures prices due to the supply shock can thus be

\footnotetext{
${ }^{17}$ It is for this same reason that corporations such as Hewlett-Packard and Siemens have successfully implemented internal prediction markets to encourage the development of successful products that might otherwise be stifled by manager disapproval.

${ }^{18}$ An example of such a supply shock could be something like Hurricane Katrina, an event which devastated much of the oil refining capacity in the United States in a single day.
} 
quantified by

$$
\frac{\partial V_{t+1}^{f+}}{\partial q_{t}} \equiv z_{1}=\frac{2}{2+\alpha+\beta} .
$$

In a similar fashion, the observable $V_{t+1}^{f-} \equiv V_{t+1}^{f, \pi}-V_{t+1}^{f, Y}$ can be expressed as

$$
V_{t+1}^{f-}=\frac{[2 \gamma(1+\alpha)-2 \delta(1+\beta)] w_{t}-2(1+\beta) s_{t}+2(1+\alpha) q_{t}+(\beta-\alpha) X_{t+1}^{*}}{2+\alpha+\beta} .
$$

Given the same supply shock, $V_{t+1}^{f-}$ will respond such that

$$
\frac{\partial V_{t+1}^{f-}}{\partial q_{t}} \equiv z_{2}=\frac{2(1+\alpha)}{2+\alpha+\beta} .
$$

With the observables $z_{1}$ and $z_{2}$ in hand, solving for $\alpha$ and $\beta$ using (13) and (14) yields $\alpha=\frac{z_{2}-z_{1}}{z_{1}}$ and $\beta=\frac{2-z_{2}-z_{1}}{z_{1}}$. In the context of the policy debate over nominal GDP versus inflation targeting described above, condition (12) can be expressed simply as the equivalent condition $z_{2}<4$. Thus, if traders' responses to supply shocks are such that $z_{2}<4$, traders would be indicating support for McCallum's proposition of superior real stabilization under nominal GDP targeting, and the converse would indicate traders' implicit support of IT proponents such as Svensson.

It should be reiterated that the application of policy futures markets to resolve the IT versus nominal GDP targeting debate is but one of many possible problems that private-sector traders can be helpful in addressing. For instance, for countries who target exchange rates as a policy goal, private-sector traders could give implied magnitudes on how effective pegs are in reducing inflation. ${ }^{19}$ However, of primary importance in this paper is demonstrating the efficiency and feasibility of monetary policymakers to rely on private-sector information in setting its policy instrument, without the problematic circularity issue arising.

\footnotetext{
${ }^{19}$ The above model does not reflect exchange rates as a goal variable, but could be easily modified to address such a question.
} 


\section{Conclusion}

In the introduction to McCallum and Nelson (1999), the authors emphasize two key characteristics monetary policy should possess: operationality and robustness. An appropriately designed policy futures market can meet both these objectives, making it a particularly appealing alternative to monetary policy based on traditional structural macromodels and policy by committee.

We improve upon the approach of Jackson and Sumner (2006) by considering a central bank that is interested in the dual goals of inflation and output stabilization as a policy objective. Equivalence between a policy futures regime and a central bank with perfect information is established. Moreover, the conclusion that the policy futures market achieves the theoretical minimum variance is preserved (given its preferences over inflation and output). These results demonstrate that such a policy regime is flexible enough to accommodate most practical monetary policy objectives, without the need for extensive information gathering by the central bank or reliance on a structural model to implement policy.

Finally, we address the intriguing potential for policy futures markets to weigh in on policy questions traditionally relegated to academia. If markets are efficient, the answers to important policy questions may be implicitly imbedded in the prices of appropriately designed policy futures. The literature on prediction market efficacy would indicate that participants in such policy futures markets need not necessarily be considered 'experts' to provide valuable information on the appropriateness or merits of policy. Indeed, a diversity of opinion seems to be the primary mechanism which makes these markets more accurate than expert views.

In considering such innovative monetary policy changes, one should keep in mind that economists at one time were generally opposed to now widely- 
accepted policy arrangements such as currency unions and inflation targeting. Given the continued interest expressed by prominent economists such as Bernanke (2007) and Mankiw (2006) in integrating the private-sector into the policy process, it is apparent that we are already moving in the direction of such a policy regime. Although economists may not yet be willing to trade in their ivory towers for a margin account, the informative potential for properly designed prediction markets as a guide to policy seems unlimited.

\section{References}

Battaglini M., 2004. Policy advice with imperfectly informed experts. Advances in Theoretical Economics 2004; 4.

Berg J, Rietz T, 2006. The Iowa electronic markets: Stylized facts and open issues. In: Hahn R, Tetlock P (Eds). Information Markets: A New Way of Making Decisions. AEI Press: Washington D.C.; pp. 142 - 169.

Bernanke B, Woodford M., 1997. Inflation forecasts and monetary policy. Journal of Money, Credit, and Banking 1997; 29; pp. 653-84.

Bernanke B., 2007. Speech at the Cato Institute 25th Annual Monetary Conference, Washington D.C.; November 14, 2007.

http://www.federalreserve.gov/newsevents/speech/bernanke20071114a.htm

Blinder A, Morgan J., 2008. Do monetary policy committees need leaders? A report on an experiment. American Economic Review 2008; 98; pp. 224-29.

Cecchetti S, Ehrmann M., 1999. Does inflation targeting increase output volatility? An international comparison of policymakers' preferences and outcomes. NBER Working Paper 7426. 
Dowd K., 1994. A proposal to end inflation. Economic Journal 1994; 104; pp. $828-840$.

Faust J, Swanson E, Wright J., 2003. Do Federal Reserve policy surprises reveal superior information about the economy? Contributions to Macroeconomics 4; number 1 .

Gürkaynak R, Wolfers J., 2006. Macroeconomic derivatives: An initial analysis of market-based macro forecasts, uncertainty, and risk. NBER Working Paper 11929.

Hahn R, Tetlock P., 2005. Using information markets to improve public decision making. Harvard Journal of Law and Public Policy 2005; 29; pp. 213 289.

Hall R.,1983. Optimal fiduciary monetary systems. Journal of Monetary Economics 1983;12; pp. 33-50.

Hanson R., 2006. Foul play in information markets. In: Hahn R, Tetlock P (Eds). Information Markets: A New Way of Making Decisions. AEI Press: Washington D.C.; pp. 126 - 141.

Hanson R., 2008. Shall we vote on values, but bet on beliefs? Journal of Political Philosophy; forthcoming.

Hanson R, Oprea R, Porter D., 2006. Information aggregation and manipulation in an experimental market. Journal of Economic Behavior and Organization 2006; 60; pp. 449 - 459 .

Hetzel R., 1990. Maintaining price stability: A proposal. Federal Reserve Bank of Richmond Economic Review 1990; March/April; pp. 53-55. 
Jackson A, Sumner S., 2006. Velocity futures markets: Does the fed need a structural model? Economic Inquiry 2006; 44; pp. 716-728.

Jackson A, Sumner S., 2009. Using prediction markets to guide global warming policy. Working paper, Bentley University.

Lombardelli, C, Talbot J, Proudman J., 2002. Committees versus individuals: An experimental analysis of monetary policy decisionmaking. Bank of England Quarterly Bulletin 2002; 42; pp. 262-273.

Mankiw G., 2006. How to decentralize monetary policy. Unpublished commentary, http://gregmankiw.blogspot.com/2006/07/how-to-decentralize-monetary-policy.html

McCallum B., 1999. Issues in the design of monetary policy rules. In: Taylor JB, Woodford M (Eds), Handbook of Macroeconomics, vol. 1C. Elsevier: Amsterdam; pp. 1483-1530.

McCallum B., 2001. Monetary policy analysis in models without money. Federal Reserve Bank of St. Louis Review 2001; July/August; pp. 145 - 160.

McCallum B., Nelson E., 1999. Performance of operational policy rules in an estimated semiclassical structural model. In: Taylor JB (Ed), Monetary Policy Rules. NBER Press: Chicago; pp. $15-45$.

Romer C, Romer D., 2000. Federal Reserve information and the behavior of interest rates. American Economic Review 2000; 90; pp. 429 - 457.

Stix H, Knell M., 2004. Three decades of money demand studies: Some differences and remarkable similarities. Oesterreichische Nationalbank Working Paper 88. 
Sumner S., 1989. Using futures instrument prices to target nominal income. Bulletin of Economic Research 1989; 41; pp. 157-62.

Sumner S., 2006. Let a thousand models bloom: The advantages of making the FOMC a truly 'open market'. Contributions to Macroeconomics 6; Article 8.

Sumner S., 2008. Will economists ever again be able to forecast a recession? Working Paper, Bentley University.

Svensson L., 1997. Inflation forecast targeting: Implementing and monitoring inflation targets. European Economic Review 1997; 41; pp. 1111-46.

Svensson L., 1999. Inflation targeting: Some extensions. Scandinavian Journal of Economics 1999; 101; pp. 337-361.

Wolfers J., 2008. Do monetary policy committees need leaders? A report on an experiment. Discussion comments; unpublished; January 2008.

Wolfers J, Zitzewitz E., 2004. Prediction markets. Journal of Economic Perspectives 2004; 18; pp.107-126.

Wolfers J, Zitzewitz E., 2006. Five open questions about prediction markets. In: Hahn R, Tetlock P (Eds). Information Markets: A New Way of Making Decisions. AEI Press: Washington D.C.; pp. 142 - 169.

Woodford M., 1994. Nonstandard indicators for monetary policy: Can their usefulness be judged from forecasting regressions? In: Mankiw NG (Ed), Monetary Policy. NBER Press: Chicago; pp. 95 - 116.

Woodford M., 2003. Interest and Prices: Foundations of a Theory of Monetary Policy. Princeton University Press: Princeton; 2003. 